\title{
Psicologia da Religião no Brasil: A Produção em Periódicos e Livros ${ }^{1}$
}

\author{
Geraldo José de Paiva² \\ Wellington Zangari \\ Marisa Moura Verdade \\ José Rogério Machado de Paula \\ David Gaspar Ribeiro de Faria \\ Denise Mendes Gomes \\ Fátima C. C. Fontes \\ Cátia Cilene Lima Rodrigues \\ Maria Luísa Trovato \\ Antônio Máspoli de Araújo Gomes \\ Universidade de São Paulo
}

\begin{abstract}
RESUMO - Apresenta-se apreciação crítica da Psicologia da Religião no Brasil, no período de 1956 a 2005, realizada com base em artigos publicados principalmente em periódicos nacionais de Psicologia. Avaliaram-se 125 artigos, segundo o tema, a teoria e a metodologia. Observou-se tendência de aumento gradativo do número de publicações. Os temas preferidos foram saúde, experiência religiosa, vocação, identidade e relações entre psicologia e religião. A produção revela utilização de teorias, conceitos e métodos da linha-mestra da Psicologia. A apreciação crítica é contextualizada em termos da origem da Psicologia da Religião no Brasil, da sua institucionalização acadêmica e dos eventos que resultaram numa literatura científica específica.
\end{abstract}

Palavras-chave: Psicologia da Religião; produção científica; produção em periódicos brasileiros.

\section{Psychology of Religion in Brazil: The Production in Journals and Books}

\begin{abstract}
A critical evaluation of Psychology of Religion in Brazil, from 1956 to 2005, based mainly on articles published in Brazilian journals of Psychology, is presented. One hundred and twenty five articles were evaluated according to their subject matter, and their theoretical and methodological dimensions. It was observed an increasing trend in the number of publications. The subject matters most studied were health, religious experience, vocation, identity and relationship between psychology and religion. The production demonstrates preference for theories, concepts and methods of Psychology mainstream. The critical evaluation is placed in the context of the history of Psychology of Religion in Brazil, its academic institutionalization and the events that resulted in a specific scientific literature.
\end{abstract}

Keywords: Psychology of Religion; scientific production; production in Brazilian journals.

A Psicologia da Religião (PR) consiste no estudo do comportamento religioso, isto é, do comportamento que se refere a um objeto transcendente, denominado "Deus" na cultura ocidental. Para a PR, esse comportamento pode ser de aceitação ou de rejeição do objeto transcendente, e esse objeto pode receber diversas outras denominações, além da predominante na cultura ocidental.

A PR no Brasil completou recentemente 50 anos, se tomarmos como início o artigo de Benkö (1956). Por ocasião desse cinquentenário, o Laboratório de Estudos em Psicologia Social da Religião, do Instituto de Psicologia da Universidade de São Paulo, com o apoio do CNPq, empreendeu uma apreciação teórico-crítica da produção da área, registrada em periódicos científicos brasileiros a partir de 1956, reconhecendo, entretanto, a existência de artigos esporádicos anteriores a essa data, geralmente em revistas de cultura (Berge, 1939). O presente artigo leva em conta essa produção, acrescentando-

1 Pesquisa financiada pelo Conselho Nacional de Desenvolvimento Científico e Tecnológico - CNPq

2 Endereço para correspondência: Instituto de Psicologia, Universidade de São Paulo. Av. Prof. Mello Moraes, 1721. São Paulo, SP. CEP 05508-030.E-mail: gjdpaiva@usp.br. lhe publicações em forma de livros, realização de eventos científicos e organização acadêmica do tópico.

\section{Produção em Periódicos Científicos}

A presente apreciação teórico-crítica assim se denominou porque pretendeu examinar a produção em PR tecendo considerações críticas acerca das teorias e dos métodos empregados nas publicações. Foram examinados 25 periódicos científicos impressos. A maior parte desses periódicos aceita contribuições das várias linhas teóricas da Psicologia. Alguns são periódicos exclusivamente voltados para a Psicanálise ou para a Psicologia Analítica. Poucos são periódicos de natureza teológica, mas abertos para estudos propriamente psicológicos. Alguns títulos ilustram as várias orientações. Em primeiro lugar consignaríamos Revista de Psicologia Normal e Patológica, Psicologia USP, Psicologia: Teoria e Pesquisa, Psicologia: Reflexão e Crítica, Temas em Psicologia. Em segundo lugar, Revista Brasileira de Psicanálise, IDE-Jornal de Psicanálise e Junguiana. Em terceiro lugar, Estudos de Religião, Perspectiva Teológica e Revista Eclesiástica Brasileira. A quase totalidade dos periódicos 


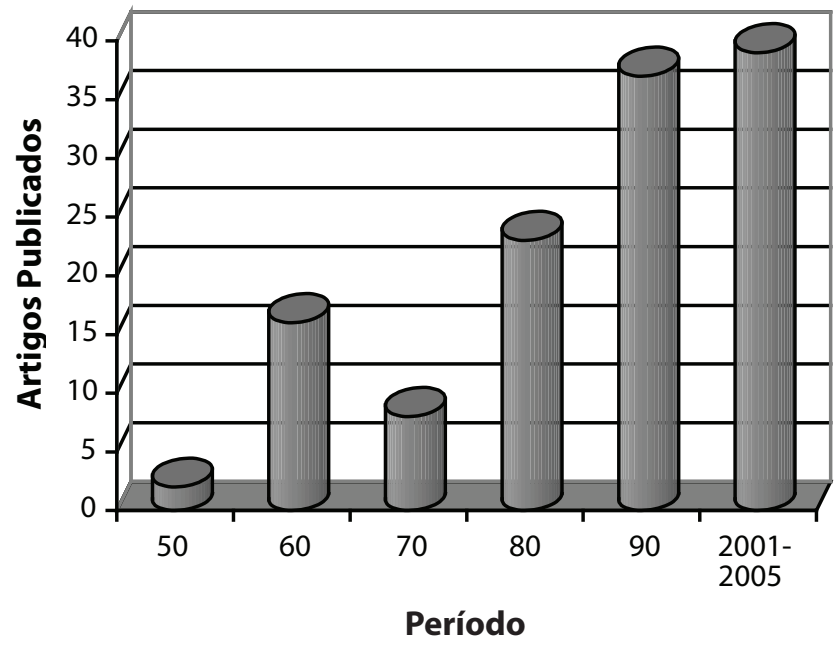

Figura 1. Frequência de artigos publicados nas décadas de 1950 a 1990 e no quinquênio 2001-2005.

se acha vinculada a instituições universitárias públicas ou confessionais, ou a associações científicas e profissionais, de várias localidades do país.

O levantamento das publicações conseguiu verificar algumas tendências nesses 50 anos de PR. A primeira delas é o número ascendente de estudos publicados, com exceção da década de 1970. A segunda é a constante multiplicidade de temas específicos em PR. A terceira é a predominância, na temática, da discussão conceitual. A quarta é o emprego progressivamente mais disciplinado das teorias psicológicas. A quinta, enfim, é o crescente rigor metodológico das pesquisas publicadas. Os parágrafos seguintes detalham cada uma das tendências apontadas.

Com relação ao número de estudos, verificou-se a ocorrência de duas publicações na década de 1950, de 16 na década de 1960, de oito na década de 1970, de 23 na década de 1980 , de 37 na década de 1990 e de 39 no primeiro lustro dos anos 2000, totalizando 125 artigos $^{3}$. A Figura 1 apresenta a frequência de artigos em PR no período em questão.

O decréscimo verificado na década de 1970 explica-se muito provavelmente pela situação política do país, que passou a exigir dos interessados em Psicologia e em PR, atenção para os problemas políticos e sociais da nação (Andery, $2001^{4}$ ). O aumento das publicações nas décadas seguintes correlaciona-se com a estruturação acadêmica da disciplina, que se tornou objeto de ensino, no nível de graduação e de pós-graduação, em algumas instituições universitárias, com a constituição de um Grupo de Trabalho permanente no âmbito da Associação Nacional de Pesquisa e Pós-Graduação em Psicologia (ANPEPP), e com a divulgação das pesquisas em PR em eventos científicos, gerais e específicos, de caráter nacional e internacional. Dentre esses eventos encontramse os seminários "Psicologia e Senso Religioso", que vêm ocorrendo, em média, a cada dois anos desde 1997. Não se

3 A relação dos artigos por ordem cronológica de publicação e por ordem de autor pode ser obtida com o primeiro autor.

4 A.A.Andery, entrevista concedida aos 28/08/2001 a David G. R. Faria, M. Luísa Trovato e Marisa M. Verdade, do Laboratório de Psicologia Social da Religião, do IP-USP. pode, contudo, desvincular o incremento das publicações em PR do aumento, igualmente verificado, de publicações em todas as áreas da Psicologia.

Os temas abordados nos artigos publicados têm mantido rica diversidade, embora alguns deles se destaquem pela frequência. Saúde, experiência religiosa, vocação religiosa/ sacerdotal, identidade religiosa e relações entre psicologia e religião têm sido os temas mais frequentes. Vêm a seguir, com menor frequência, agressividade, arquétipos, atitudes, comunicação, corpo, culpa, escrúpulo, personalidade, representação social, sexualidade e simbolismo.

A predominância da temática conceitual é sintomática de uma situação de ambiguidade no campo da Psicologia, relativamente a um tema em grande parte estranho, que Freud adjetivaria como unheimlich. Provavelmente, a forte tradição psicopatológica francesa do fenômeno religioso (Déconchy, 1970) e o relativo desconhecimento da literatura norte-americana e européia da área (Capps, Rambo \& Ransohoff, 1976) estão na origem do interesse pelo esclarecimento conceitual. Tal esclarecimento tem sido procurado no diálogo com a psicanálise e a psicologia analítica, com a psicologia social, do desenvolvimento e da personalidade, e com a teologia.

A quarta tendência detectada no levantamento é a do emprego mais consciencioso das teorias psicológicas no estudo dos fenômenos religiosos. Verificou-se, com efeito, que nas publicações da década de 1960, e mesmo nas de 1970 e 1980 , vários estudos não se fundamentavam em teorias psicológicas nítidas, apresentando, ao contrário, ou ausência de teoria ou associação frouxa de pontos de vista teóricos. Na década de 1990 e nos cinco primeiros anos de 2000, ao contrário, essa fundamentação difusa ou indeterminada desaparece. Os dados mostram, no entanto, que em todo o período estudado, a maior parte dos estudos fundamentou-se em teorias psicológicas reconhecíveis, de natureza psicodinâmica, cognitiva ou fenomenológico-existencial.

Finalmente, a pesquisa constatou que, embora tenha prevalecido no correr das décadas a abordagem conceitual, tem crescido o número de estudos empíricos e aplicados. Refletindo, certamente, um viés de muitos estudos psicológicos no Brasil, que preferem o qualitativo ao quantitativo, os estudos empíricos e aplicados têm sido predominantemente de caráter qualitativo. Note-se, contudo, que na década de 1960, 50\% dos estudos publicados lidaram com dados e com tratamento quantitativos, uma vez que o instrumento empregado eram testes de orientação vocacional. Esse percentual coincide com o verificado na década de 1990.

\section{Produção de Livros e Capítulos de Livros}

A publicação científica em PR sob forma de livros ou capítulos de livro é relativamente recente e, pode-se dizer, subsidiária à publicação em periódicos. Com exceção da notável obra do jesuíta Leonel Franca, Psicologia da Fé, da década de 1930 (Franca, 1933), do livro Psicologia da Religião, de Merval Rosa, da década de 1970 (Rosa, 1971) e de Psicologia da Religião, de Antonius Benkö, da década de 1980 (Benkö, 1981), a publicação brasileira de livros ou capítulos científicos ocorreu na década de 1990 e nos anos 
posteriores. Essas primeiras obras não são da mesma natureza que as atuais porque, no caso de Franca, o livro tem como principal referência a filosofia, a teologia e a biografia de crentes e descrentes; no caso de Rosa, o trabalho constitui versão de sua dissertação de mestrado apresentada nos Estados Unidos; e, no caso de Benkö, a obra é simples introdução às vertentes clássicas da Psicologia no tratamento do fenômeno religioso. A partir da década de 1990, no entanto, os textos resultam geralmente de trabalhos apresentados em eventos científicos, dentre os quais se destacam os seminários "Psicologia e Senso Religioso". Constam, entre esses, os livros de E. Valle (1998), Psicologia e experiência religiosa; de M. Massimi e M. Mahfoud (1999), Diante do mistério: Psicologia e senso religioso; de G. J. de Paiva, A religião dos cientistas: uma leitura psicológica (2000) e Entre necessidade e desejo: diálogos da Psicologia com a Religião (2001); de V. A. Angerami-Camon, Vanguarda em psicoterapia existencial (2004a) e Espiritualidade e prática clínica (2004b); de A Holanda (2004), Psicologia, religiosidade e fenomenologia; de G. J. de Paiva e W. Zangari (2004), A representação na religião: perspectivas psicológicas; e de M. M. Amatuzzi (2005), Psicologia e espiritualidade. A maioria dessas publicações trata das relações entre psicologia e religião em diversas articulações. Literatura, história da cultura, clínica e psicoterapia(s), sexualidade, desenvolvimento ao longo da vida, modalidades do desejo, reinterpretação winnicottiana da ilusão, mudança da modernidade para a pós-modernidade, encontro de culturas, expressões afro-brasileiras, religião popular, dilema ateísmo-devoção, espiritualidade e sagrado constituíram lugares de encontro entre religião e psicologia. Quase todos esses tópicos fazem parte da discussão recente da PR internacional e expressam a qualidade da informação de nossos pesquisadores.

\section{Origens da PR no Brasil}

A PR no Brasil surgiu por influência européia. Em São Paulo, o médico italiano Enzo Azzi, da PUC-SP, foi quem confiou, na década de 1950, ao psicólogo holandês Theo van Kolck, a direção de um Departamento de Psicologia da Religião na mesma Universidade, fortemente influenciada pela Universidade Católica de Lovaina (Leuven) e menos marcadamente pela Universidade Católica de Milão (Andery, 2001). Na mesma época foi criada, em São Paulo, a Associação de Psicologia Religiosa, que reunia psicólogos, médicos, antropólogos e sacerdotes, sob a direção de Theo van Kolck. Entre 1960 e 1966, a Associação organizou alguns encontros, com boa afluência de interessados, em torno de temas diversos, tais como: estrutura da personalidade e religiosidade, religião e existencialismo, Freud e a religião (Andery, 2001).

No Rio de Janeiro, em meados da década de 1950, o sacerdote húngaro, com passagem pela Itália, Antonius Benkö, empreendeu as primeiras pesquisas empíricas em PR na PUCRJ. Posteriormente, a mesma instituição forneceu valiosas contribuições para a psicologia social da religião graças às pesquisas de Monique Augras (1983), especialmente no campo das religiões afro-brasileiras e do catolicismo popular. No Rio Grande do Sul, também a PUC desde cedo abrigou em sua revista de Psicologia - Psico -, artigos de PR (Finkler, 1971, 1973). Deve-se reconhecer o cariz confessional dessas iniciativas que, no entanto, não obstou ao desenvolvimento da psicologia como ciência autônoma.

$\mathrm{Na}$ universidade pública, a inserção da PR ocorreu em meados da década de 1980, na Universidade de São Paulo e, posteriormente, na Universidade Federal de Minas Gerais (UFMG) e na Universidade de Brasília (UnB). Na Universidade de São Paulo, começaram a ser oferecidas disciplinas de PR, primeiro nos cursos de pós-graduação e, a seguir, no curso de graduação em Psicologia, com abertura para os mais diversos cursos de graduação da Universidade. Tanto na Universidade de São Paulo como na Universidade de Brasília, na Universidade Católica de Brasília e na Pontifícia Universidade Católica de Campinas, alguns pós-graduandos dos vários programas de pós-graduação em Psicologia acabaram realizando suas dissertações de mestrado e suas teses de doutorado em temas da PR. Em 1998, foi constituído o Grupo de Trabalho "Psicologia \& Religião", da Associação Nacional de Pesquisa e Pós-Graduação em Psicologia (ANPEPP), que conta atualmente, entre seus membros, com professores das universidades públicas de São Paulo e Minas Gerais, das universidades católicas de São Paulo, Brasília e Campinas e da Universidade Metodista de São Paulo. O Grupo de Trabalho assumiu a realização dos seminários bienais "Psicologia e Senso Religioso", que aconteceram na Universidade Federal de Minas Gerais, na Universidade de São Paulo e na PUC-Campinas. Como foi apontado, grande parte da literatura especializada em PR, sob forma de livros ou de capítulos de livro, deriva desses eventos científicos. Registre-se, finalmente, a criação, no Programa de PósGraduação em Psicologia Social da USP, do Laboratório de Psicologia Social da Religião, cujas atividades incluem a realização de pesquisas com as respectivas publicações.

\section{Apreciação Geral}

O levantamento dos artigos em periódicos, subsidiado pelo levantamento de publicações sob forma de livros ou de capítulos, permite algumas apreciações de caráter geral.

A primeira é a de que a PR vem acompanhando, na teoria e na metodologia, a linha-mestra da Psicologia. Decorrência disso é sua crescente aceitação por parte do corpo acadêmico. A Psicologia no Brasil, como atividade acadêmica, vem alcançando níveis de excelência internacionais, atestados pelas exigências editoriais dos periódicos. Apesar da limitação à circulação internacional imposta pela língua portuguesa, tanto a fundamentação teórica como o procedimento metodológico dos artigos são verificados segundo critérios internacionais. $\mathrm{O}$ atendimento a esses critérios por parte dos que publicam em PR tem aumentado notavelmente na década de 90 e nos anos posteriores, o que assegurou à $\mathrm{PR}$ o reconhecimento acadêmico, como um nicho específico da Psicologia.

Não se pode dizer, contudo, que a PR seja das áreas mais consolidadas da Psicologia. De fato, comparativamente com outras áreas, são poucos os pesquisadores envolvidos sistematicamente com PR. Núcleos universitários dedicados à pesquisa e à docência, para não dizer à extensão, nessa área contam-se em pequeno número. Enquanto a área de Ciências 
da Religião mantém vários centros de estudos pós-graduados, a PR, como tal, ainda não tem um programa sequer de pósgraduação, embora existam mestres e doutores, formados nos vários programas de pós-graduação em Psicologia, com dissertações e teses em temas da PR

Um fator complicador para a apreciação da situação da PR, é o interesse pela Psicologia da Espiritualidade, identificada com a PR sem acurado exame de suas semelhanças e diferenças. Verifica-se, na população universitária e no público em geral, grande interesse pelo tratamento psicológico do fenômeno religioso. Não é claro, contudo, o móvel desse interesse nem mesmo no meio universitário. Tem-se verificado com frequência que estudantes de Psicologia e de outras áreas recorrem à disciplina PR para resolverem problemas pessoais, levantados pelo encontro da religião que trouxeram da família com a perspectiva acadêmica, sobretudo psicológica. O conteúdo curricular das disciplinas de Psicologia, de modo geral, não inclui referência à religião, de modo que a PR é procurada, pelos estudantes, como um recurso para a superação do desconforto resultante do (des) encontro entre religião e ciência psicológica.

A influência da Escola de Lovaina se fez sentir em dois momentos na PR brasileira: na década de 1960 e a partir do fim da década de 1980. Lovaina sempre promoveu uma abordagem propriamente psicológica ao estudo da religião, de modo que as pesquisas publicadas na Revista de Psicologia Normal e Patológica, nos anos 60, e as realizadas no Laboratório de Psicologia Social da Religião sempre se caracterizaram como Psicologia da Religião, e não como Psicologia Religiosa. Quando, na década de 1960, se constituiu a Associação Brasileira de Psicologia Religiosa, um de seus inspiradores, Alberto A. Andery (1963) delineou o enfoque propriamente psicológico do fenômeno religioso, distinguindo-o de outros enfoques, legítimos, porém não psicológicos. Embora a Associação não tenha tido longa vida, porquanto extinta na década de 1970, cumpre assinalar sua existência ao longo de cerca de 10 anos, durante a qual reuniu um grupo pioneiro de estudiosos de várias especialidades, orientados, quando psicólogos, pela psicanálise e pelo que se pode chamar psicologia cognitiva. Desse grupo fizeram parte pesquisadores ativos até hoje, como E. Valle, na psicologia social, e O. de Mello Franco Filho, na psicanálise.

A partir do final dos anos 80, grande parte dos estudos em PR demonstra a influência de Lovaina (Leuven e LouvainLa-Neuve), que se pode resumir no esforço por conjugar dois níveis de estudo do fenômeno religioso, o do consciente e o do inconsciente, conjugando, igualmente, teorias e metodologias adequadas a cada nível (Corveleyn \& Hutsebaut, 1998; Vergote, 1983). Na tentativa de se abordar complementarmente esses dois ângulos de estudo, pode-se citar a pesquisa que investigou a relação que cientistas avançados de uma grande universidade brasileira estabeleceram ou deixaram de estabelecer entre sua ciência e sua religião (Paiva, 1993, 2000). A maior influência de Lovaina reside, contudo, na abordagem francamente psicológica da vivência religiosa e no cuidado em estabelecer a base empírica dos estudos. Para a consolidação dessa influência tem contribuído a participação pessoal de pesquisadores líderes de Lovaina nos seminários "Psicologia e Senso Religioso".
Dentro da latitude de enfoques apontada, outras teorias, como a do sueco H. Sundén, têm servido de inspiração para dissertações e teses. Sundén merece citação especial (Belzen, 1996), pois que sua importância só recentemente vem sendo considerada no âmbito acadêmico internacional, como atesta o número especial, a ele dedicado em 1987, do Journal for the Scientific Study of Religion. O levantamento das publicações em periódicos revelou, contudo, que a abordagem psicodinâmica, tanto freudiana como junguiana e, recentemente, winnicottiana, tem predominado desde o início, fora dos locais diretamente influenciados por Lovaina. Isso parece dever-se à estrutura da abordagem psicodinâmica, aberta para a consideração das abrangentes relações entre o psiquismo e o interesse religioso. Com essa abordagem, portanto, registram-se muitos estudos de natureza conceitual, a encaixar-se no modelo da ilusão ou dos arquétipos.

O cenário religioso brasileiro, habitado por grande profusão de religiões, tem favorecido alguns estudos peculiares, tendo como objeto as religiões afro-brasileiras (candomblé e umbanda), o budismo e algumas novas religiões japonesas (Seicho-no-iê e Perfect Liberty). O enfoque mais frequente tem sido, nesses casos, o psicossocial, sob forma de influência do grupo ou de constituição da identidade. A pesquisa da função mediúnica, por exemplo, foi estudada na dimensão da influência social e das características de personalidade dos médiuns (Zangari, 2003). Como trabalho de pós-doutorado, ambos os aspectos foram estudados de forma experimental (Zangari, 2007). A constituição da identidade foi pesquisada em budistas e fiéis de novas religiões japonesas tanto do ponto de vista psicossocial, da pertença grupal, como do ponto de vista pessoal, da construção simbólica ou imaginária (Paiva \& cols., 2000; Paiva, 2005). Um resultado inesperado desses estudos, inesperado em razão da ênfase da Psicologia da Personalidade no indivíduo e da Psicologia Social no grupo, foi a convergência entre os vetores psicossocial e pessoal, de forma a estabelecer-se, com bastante probabilidade, que a filiação grupal reclama a construção simbólica e a construção simbólica reclama a filiação grupal (Paiva, 2004).

Outros tópicos vêm merecendo a atenção dos pesquisadores. Dentre eles, a identidade do sacerdote católico na situação pós-moderna (Paula, 2001) e a posição do psicólogo clínico frente à religião dos pacientes (Ancona-Lopez, 2004, 2005). Tem sido possível evitar a polarização religiosa da atividade clínica e, ao mesmo tempo, evidenciar a conveniência da abertura do psicólogo à dinâmica da opção religiosa dos pacientes e, mesmo, a necessidade de um posicionamento refletido do psicólogo em relação a sua própria opção religiosa ou irreligiosa.

O reconhecimento da PR pela comunidade acadêmica brasileira tem-se manifestado de diversas formas. "Psicologia da Religião" é um tópico inserido na classificação das várias especializações da Psicologia pelo Conselho Nacional de Pesquisa Científica e Tecnológica (CNPq) e pela Sociedade Brasileira de Psicologia (SBP), e tem sido matéria frequente de publicação do periódico da Sociedade, Temas em Psicologia. É também a razão do Grupo de Trabalho Psicologia \& Religião da ANPEPP e de um Grupo de Pesquisa do CNPq. A organização dos seminários "Psicologia e Senso Religioso" tem recebido auxílio regular das agências de fomento, como a Fundação de Amparo à Pesquisa do Estado de São 
Paulo (FAPESP) e o CNPq, além dos auxílios concedidos por instituições universitárias públicas, confessionais ou particulares, e pelos programas de pós-graduação amparados pela Coordenação de Aperfeiçoamento do Pessoal de Nível Superior (CAPES). As agências de fomento, no âmbito federal ou estadual, têm, também, financiado a participação de pesquisadores em congressos internacionais de PR, como os promovidos pela Società Italiana di Psicologia della Religione, pelos psicólogos europeus da religião e, ultimamente, pela International Association for the Psychology of Religion (IAPR).

Apesar da grande diversidade de temas na produção levantada ao longo das décadas nos periódicos (agressividade, arquétipos, saúde, atitudes, comunicação, corpo, culpa, escrúpulo, espiritualidade, identidade, personalidade, psicologia da religião, psicologia e teologia, representação social, sexualidade, simbolismo, vivência/experiência religiosa, vocação religiosa/sacerdotal), é possível reconhecer algumas tendências temáticas.

A década de 60 teve como característica a produção de uma Psicologia que gravitava ao redor de um núcleo de pesquisadores confessionais. Dos 17 artigos do período, com efeito, 10 se propõem a instrumentar psicologicamente os responsáveis eclesiásticos, visando a seleção adequada de candidatos à vida sacerdotal e religiosa. Ressalve-se, contudo, o rigor metodológico desses estudos e a segura orientação epistemológica por vezes enunciada. Essa psicologia religiosa teve sua continuidade comprometida com os movimentos políticos da década de 70, que deslocaram o interesse para aspectos mais políticos do que psicológicos do viver religioso e diminuíram visivelmente a produção da área. Registre-se, a propósito, que alguns dos estudiosos de PR deram origem, nessa época, à vertente da Psicologia Comunitária e à Associação Brasileira de Psicologia Social (ABRAPSO).

A década de 80 assistiu ao reflorescimento da produção. Dobra o número de temas, em relação à década anterior, e intensifica-se o estudo das relações entre religião e psicologia, incluindo-se o papel do psicólogo frente ao comportamento religioso. Cresce, igualmente, o interesse pelo tema das relações entre religião, saúde e práticas psicoterapêuticas.

A década de 90 e o primeiro lustro de 2000 mantêm o interesse pelas relações entre psicoterapia, saúde e religião, e acrescentam o interesse pela experiência religiosa, no sentido de se estudar os processos psíquicos da vivência religiosa, desde o catolicismo tradicional até as religiões minoritárias, como o candomblé, a umbanda, o budismo e as novas religiões japonesas.

Um dado claro do levantamento é a primazia do método conceitual, utilizado em $50 \%$ dos artigos publicados. Vinte e dois por cento dos trabalhos utilizaram algum método empírico. A preferência pelo método conceitual coincide com a abordagem da pesquisa: quase $60 \%$ dos trabalhos são realizados à luz da perspectiva psicodinâmica, seja da psicanálise (freudiana e winnicottiana), seja da psicologia analítica (junguiana). Como dito acima, a perspectiva psicodinâmica abre-se para considerações abrangentes, e daí conceituais, entre religião e psiquismo. Os cerca de $22 \%$ de artigos empíricos têm como base alguma teoria de natureza cognitiva.
Finalmente, cabe registrar a articulação de avaliações teórico-conceituais com algum método empírico, sobretudo nas análises aplicadas, que correspondem a $15 \%$ da totalidade dos trabalhos. Esses artigos são da lavra de autores com perspectiva psicodinâmica, atentos à conveniência de se descer da análise conceitual e abstrata para a realidade empírica.

\section{Considerações Finais}

O levantamento da produção científica em PR, principalmente nos periódicos, entre 1956 e 2005, permite acompanhar o que a PR no Brasil tem realizado concretamente e, por contraste, o que ela não tem sido, em termos de temas, teorias e métodos. A pesquisa permite, também, vislumbrar possibilidades e tendências da área. Forçoso é reconhecer que a PR no Brasil é um empreendimento ainda em vias de consolidação. Não data, com efeito, de muito tempo a introdução sistemática dessa especialidade entre as disciplinas de graduação e de pós-graduação de algumas instituições de ensino superior, condição para se despertar interesse genuíno pela temática, gerar pesquisas, dissertações e teses, promover o intercâmbio nacional e internacional e prover a circulação da informação científica por meio de publicações. Ainda assim, surpreende o progresso da área a partir da década de 1990, progresso que deve ser atribuído precisamente à coordenação de esforços resultante da inserção da PR na Academia. Nota-se, contudo, a quase completa ausência de assuntos contemporâneos importantes, como a negação da fé ou o ateísmo; a desfiliação institucional; o comportamento ligado a religiões não tradicionais nem hegemônicas, como o budismo, o islamismo, o judaísmo e as religiões indígenas; o lugar da experiência religiosa na sociedade pós-moderna ou pós-secular; e a religião na atividade profissional do psicólogo. Do ponto de vista teórico, parece desejável complementar o interesse pela vertente cultural com o desenvolvimento da vertente etológica do comportamento religioso, interessada na "naturalidade" desse comportamento, ou seja, nas condições bioevolutivas de sua estruturação. Finalmente, no que tange à metodologia, é desejável a utilização em maior escala da abordagem quantitativa, inclusive para o intercâmbio com grande parte do que se produz em PR em outras partes do mundo.

\section{Referências}

Amatuzzi, M. M. (2005). Psicologia e espiritualidade. São Paulo: Paulus.

Ancona-Lopez, M. (2004). Representação de Deus em pósgraduandos em psicologia clínica. Em G. J. de Paiva \& W. Zangari (Orgs.), A representação na religião: perspectivas psicológicas (pp.79-88). São Paulo: Loyola.

Ancona-Lopez, M. (2005). A espiritualidade e os psicólogos. Em M. M. Amatuzzi (Org.), Psicologia e espiritualidade (pp.147160). São Paulo: Paulus.

Andery, A. A. (1963). O conceito de psicologia religiosa. Revista de Psicologia Normal e Patológica, 9, 527-535.

Angerami-Camon, V. A. (2004a). Vanguarda em psicoterapia fenomenológico-existencial. São Paulo: Thomson. 
Angerami-Camon, V. A. (2004b) Espiritualidade e prática clínica. São Paulo: Thomson.

Augras, M. (1983). O duplo e a metamorfose: a identidade mítica em comunidades nagô. Petrópolis: Vozes.

Belzen, A J. (1996). Beyond a classic: Hjalmar Sundén's role theory and contemporary narrative psychology. The International Journal for the Psychology of Religion, 6, 181-189.

Benkö, A. (1956). Um ensaio de exame psicológico de seminaristas. Revista de Psicologia Normal e Patológica, 2, 423453.

Benkö, A. (1981). Psicologia da Religião. São Paulo: Loyola.

Berge, D. (1939). A estrutura fundamental do sentimento religioso à luz da psicologia experimental. A Ordem, 19, 125150.

Capps, D., Rambo, L., \& Ransohof, P. (1976). Psychology of Religion. A guide to information sources. Detroit: Gale Research.

Corveleyn, J., \& Hutsebaut, D. (Orgs.) (1998). Psychoanalysis, Phenomenological Anthropology and Religion. Lovaina/ Amsterdam/Atlanta: Leuven University Press/Rodopi.

Déconchy, J. P. (1970). La psychologie des faits religieux. Em H. Desroche \& J. Séguy (Orgs.), Introduction aux sciences humaines des religions. (pp. 145-174). Paris: Cujas.

Finkler, P. (1971). O psicólogo perante a religião: Psico (PUCRS), 2, 36-38.

Finkler, P. (1973). Contribuição para a psicologia da vida espiritual. Psico (PUCRS), 5-6, 71-76.

Franca, L. (1933). A psicologia da fé. Rio de Janeiro: Agir.

Holanda, A (2004). Psicologia, religiosidade e fenomenologia. Campinas: Alínea.

Massimi, M., \& Mahfoud, M. (Orgs.) (1999). Diante do mistério: psicologia e senso religioso. São Paulo: Loyola.

Paiva, G. J. de (1993). Itinerários religiosos de acadêmicos: um enfoque psicológico. Tese de Livre-Docência, Universidade de São Paulo, São Paulo.

Paiva, G. J. de (2000). A religião dos cientistas: uma leitura psicológica. São Paulo: Loyola.

Paiva, G. J. de (2001). Entre necessidade e desejo: diálogos da psicologia com a religião. São Paulo: Loyola.
Paiva, G. J. de (2004). Identidade e pluralismo: identidade religiosa em adeptos brasileiros de novas religiões japonesas. Psicologia: Teoria e Pesquisa, 20, 21-29.

Paiva, G. J. de (2005). Sincretismo e pós-modernidade na construção imaginária e simbólica da identidade religiosa no encontro entre cristianismo e budismo (relatório ao CNPq de Bolsa de Produtividade, $n^{\circ}$ 300791/91-7)

Paiva, G. J., Faria, D. G. R., Gomes, D. M., Gómez, M. L. T., Lopes, R., Nunes, L. C., Verdade, M. M., \& Zangari, W. (2000). Processos psicológicos de conversão religiosa: imaginário e simbólico, categorização e prototipicalidade. Psicologia Clínica (PUCRJ), 12, 151-169.

Paiva, G. J. de, \& Zangari, W. (2004). A representação na religião: perspectivas psicológicas. São Paulo: Loyola.

Paula, J. R. M. de (2001). Valores e pós-modernidade na formação do clero católico. Dissertação de Mestrado, Universidade de São Paulo, São Paulo.

Rosa, M. (1971). Psicologia da Religião. Rio de Janeiro: Casa Publicadora Batista.

Valle, E. (1998). Psicologia e experiência religiosa: estudos introdutórios. São Paulo: Loyola.

Vergote, A (1983). Religion, Foi, Incroyance. Etude psychologique. Bruxelas: P. Mardaga.

Zangari, W. (2003). Incorporando papéis: uma leitura psicossocial do fenômeno da mediunidade de incorporação em médiuns de Umbanda. Tese de Doutorado, Universidade de São Paulo, São Paulo.

Zangari, W. (2007). Experiências anômalas em médiuns de Umbanda: uma avaliação fenomenológica e ontológica. Boletim Academia Paulista de Psicologia, 27, 67-86.

Recebido em 10.12.07

Primeira decisão editorial em 19.11.08

Versão final em 03.04.09

Aceito em 16.04.09 